\title{
Crystallographic Texture Evolution of Aluminum Alloy 3104 in the Drawn and Wall Ironing (DWI) Process
}

\author{
André Luís Teixeira Martins ${ }^{a}$, Antonio Augusto Couto ${ }^{a, b}{ }^{\circledR}$, Nelson Batista de Lima ${ }^{b}$, \\ Gisele Fabiane Costa Almeida ${ }^{a, b} *$ (두) \\ ${ }^{a}$ Universidade Presbiteriana Mackenzie, Escola de Engenharia, São Paulo, SP, Brasil \\ ${ }^{b}$ Instituto de Pesquisas Energéticas e Nucleares, Centro de Ciência e Tecnologia de Materiais, \\ São Paulo, SP, Brasil
}

Received: January 1, 2019; Revised: August 5, 2019; Accepted: December 5, 2019

\begin{abstract}
Aluminum beverage cans should have very specific crystallographic textures to increase productivity, reduce losses and reduce the amount of material. The present work seeks to add information on the crystallographic texture of aluminum alloy $3104 \mathrm{H}-19$ during the different manufacturing steps, which undergoes a flat sheet of metal for a cylindrical body. The work scope encompasses from the cup drawing to the final ironing operation and its objective is to add information on the texture evolution of the aluminum alloy undergoes in the intermediary steps. Crystallographic texture continues to change from the drawn cup through the ironing stages. This rotation is assumed to be a grain alignment with the plastic flow of the material.
\end{abstract}

Keywords: Aluminum alloy; Beverage can; Crystallographic Texture.

\section{Introduction}

The relevance of texture in the formability of rolled metals has been widely researched and some manufacturing processes go to great lengths to assure the adequate texture is present in their final products. The aluminum beverage can and end industry and their metal suppliers, given the production processes used, are very much aware of the importance of having material with very specific crystallographic textures. The well-known earing effect, its location in relation to the rolling direction and its intensity, unavoidable because of anisotropy in aluminum alloys, can affect in significant ways the performance of the drawn and wall ironed (DWI) can body manufacturing processes ${ }^{1}$. If a well-balanced texture is not present, with its specific Cube $(\{001\}<100>)$ and rolling texture intensities ( $\beta$-fiber, Copper $\{112\}<111>$, $\mathrm{S}\{123\}<634>$, and Brass $\{110\}<112>$ ), and Goss $\{110\}$ $<001>$, ears may form during ironing causing metal to break free eventually leading to failure and machine down time ${ }^{2}$. The drawability of cups and the ironing of cans aluminum alloy rolled sheets, their texture, and the resulting earing position and intensity, were reported in many studies ${ }^{1-5}$. Great part of the knowledge developed empirically and, in such studies, generated solutions to minimize the results of the anisotropic characteristics present in rolled aluminum products, such as non-round cut edges and balanced textures ${ }^{5}$. Research related to other important aspects known to influence performance, such as microstructure, design of tools and materials, lubrication and tribological characteristics are also available ${ }^{6-14}$. To produce a can is necessary intermediate steps that goes through in transformation from a rolled sheet

*e-mail: gisele_fab@hotmail.com into a cylindrical shaped body. In his work, H. Merchant et al. measured a decrease in mechanical properties of the alloy 3004 after the first drawing operation in the cup wall and afterwards an increase during the ironing operations ${ }^{15}$. In the same work, a texture rotation is mentioned with differences between the cup top wall, where sizing occurs and thus a significant amount of strain hardening, and the mid wall. There are operations that use only two ironing dies, the present study illustrates the texture evolution of a three-die operation. During the interaction of the metal with the dies whilst plastic deformation occurs temperatures can reach around $100{ }^{\circ} \mathrm{C}$ on the first iron, altering the material's characteristics as a function of both cold working and thermal recovery ${ }^{16}$. After the conclusion of the ironing steps, $\mathrm{H}$. Merchant et. al. notes a rotation of the microband alignment in the direction of the can axis ${ }^{15}$. In the drawing and ironing processes the balanced texture is a very important feature, and ears caused by crystallographic disposition tendencies can become a problem ${ }^{2}$. Large ears at $0^{\circ}$ and $180^{\circ}$ are known to cause metal scrap (sometimes called clip offs) that jam the production machinery.

The present paper seeks to add information about the crystallographic texture evolution of the aluminum alloy $3104 \mathrm{H}-19$ during the different steps it undergoes from a flat sheet of metal to a beverage can.

\section{Materials and Methods}

The material used in the present paper is the aluminum alloy 3104-H19. The chemical composition of the 3104 alloy, acquired by atomic absorption spectroscopy, is below in Table 1. 
Table 1. Chemical composition of AA 3104 aluminum alloy acquired by atomic absorption spectroscopy.

\begin{tabular}{cccccccc}
\hline Alloy & $\mathrm{Cu}$ & $\mathrm{Mn}$ & $\mathrm{Mg}$ & $\mathrm{Fe}$ & $\mathrm{Zn}$ & $\mathrm{Si}$ & $\mathrm{Ti}$ \\
\hline 3104 & 0,29 & 0,87 & 0,70 & 0,42 & 0,08 & $\mathrm{~N} / \mathrm{I}$ & N/I \\
\hline
\end{tabular}

The aluminum coil is fed by a mandrel into a double action vertical mechanical press, usually called a cupper, fit with multiple dies for cutting the blanks and drawing the cups. This is the first operation that plastically deforms the metal. During the cup drawing a top wall thickening effect occurs due to the force applied by a blank-holder, often called a draw pad, while the metal flows around the draw die radius.

The cup is then transported to horizontal presses where it is redrawn and then ironed successively three times in the same press stroke. The ironing operation consists of thinning the wall of the new diameter cup after the redraw stage to flow metal against the punch movement direction to increase the height of the cylindrical body. The can bottom is conformed subsequently after the last ironing operation by tools that usually have titanium nitride (TiN) surface treatment to reduce friction coefficients and prolong useful life due to wear.

The pole figures were obtained using a Rigaku Dmax 2000 diffractometer with an automatic goniometer. The radiation Mok $\alpha 1\left(\lambda=0.7093 \AA\right.$ ) was used with a $5^{\circ}$ angular step and 5 seconds dwell time. The planes chosen were (111), (200), (220), and (311).

The pole figures were generated in each of the 5 intermediate steps briefly mentioned above, their description can be seen in Table 2. Figure 1 is a picture of the different steps used to generate the pole figures. Furthermore, samples were acquired from the intermediate steps at $0^{\circ}, 45^{\circ}$, and $90^{\circ}$ in relation to the rolling direction. Figure 2 shows the area used to cut samples of $25 \times 25 \mathrm{~mm}$ from the different angles to generate the pole figures. The gauge percentage reduction practiced in the progressive steps were 0 on the redraw, 25 on the first ironing operation, 30 , and 40 respectively for the second and third. A total reduction, considering the initial and final gauge and not considering the thickening effect caused by the cup sizing, was approximately 67 percent. It is worthwhile mentioning that the rolling direction, which is clearly discernible in a flat sheet of rolled material, once deformed plastically into a cylindrical body, assumes the form of a curve, sometimes called a loop line. Figure 3 illustrates the shape assumed by straight rolling direction lines after drawing and the sequential ironing operations. When measuring the poles figures the ironing direction, or the can axis, was assumed as the rolling direction.

\section{Results and Discussion}

\subsection{Pole figures}

The pole figures that follow show the planes (111) and (200), as the metal progresses through the five stages
Table 2. Sequential progress of the manufacturing sub-processes and their description.

\begin{tabular}{cc}
\hline Step Number & Process Description \\
\hline 1 & Cup Drawing \\
2 & Redrawing \\
3 & $1^{\text {st }}$ ironing die \\
4 & $2^{\text {nd }}$ ironing die \\
5 & $3^{\text {rd }}$ ironing die \\
\hline
\end{tabular}

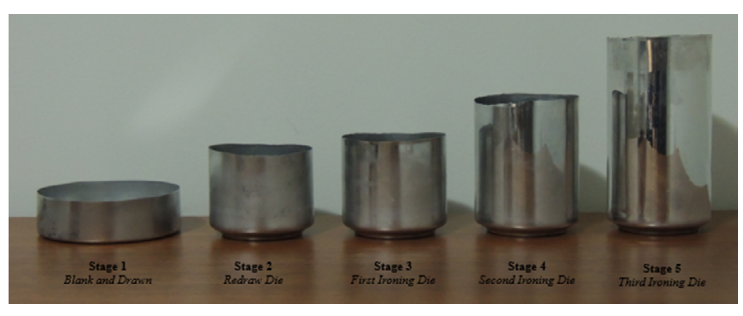

Figure 1. Sequential steps in the can body manufacturing process used to generate the pole figures.

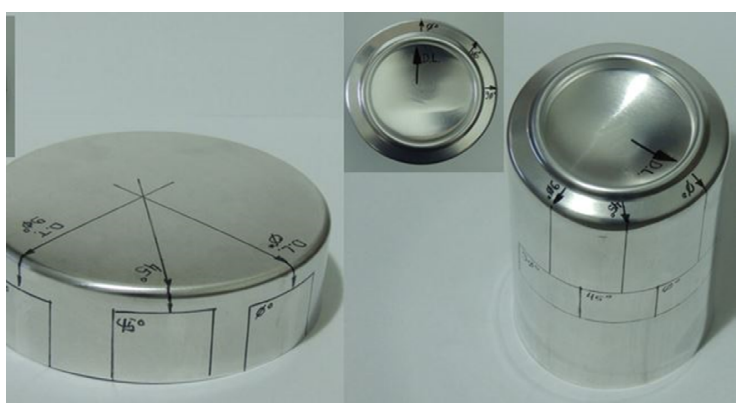

Figure 2. The first stage (drawn cup) and last stage (after the $3^{\text {rd }}$ ironing die) used in acquiring samples forming the different angles in relation to the rolling direction.

from drawing to final ironing. Each plane will have three progressions, one for samples removed from the original rolling direction, which coincides with the $0^{\circ}$ samples, and two others from $45^{\circ}$ and $90^{\circ}$ respectively. The pole figures are shown in Figures 4 until 9. The results for all planes sampled at $0^{\circ}$ indicate a slight sharpening of the deformation texture present at drawing, especially at the third stage ( $1^{\text {st }}$ ironing die). Because of the warping of the original rolling lines and because the can cut-edge, or ironing direction, was used as the rolling direction for the $45^{\circ}$ and $90^{\circ}$ samples a pole figure alteration is noticeable from the $1^{\text {st }}$ to the $5^{\text {th }}$ stage for all samples removed at $45^{\circ}$ and $90^{\circ}$. The samples removed at $45^{\circ}$ appear to rotate, more intensely at the redraw (stage 2 ), and gradually from the $1^{\text {st }}$ to the $3^{\text {rd }}$ ironing operation ( $5^{\text {th }}$ stage), becoming akin to the pole figures obtained from the $0^{\circ}$ samples after the $5^{\text {th }}$ stage. Similarly, the samples 

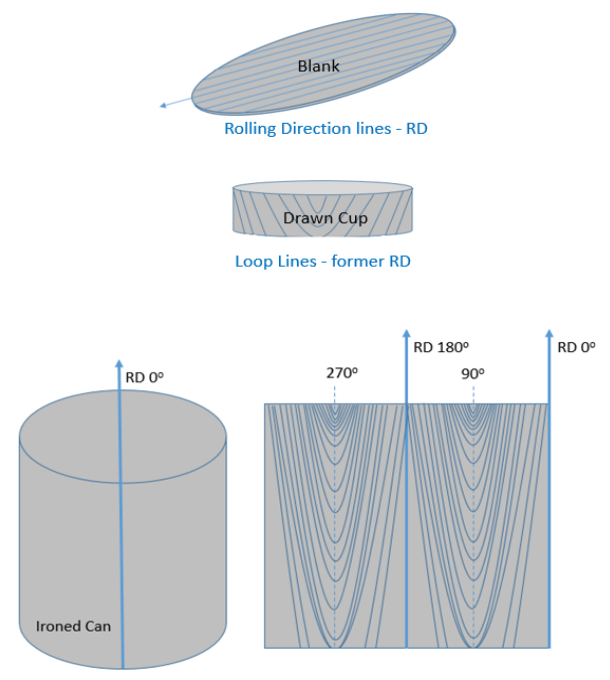

Figure 3. Blank with rolling direction lines, drawn cup, ironed can, and can wall illustrating the result of plastic deformation on the RD lines to form a cylindrical body.

measured at $90^{\circ}$ rotate to become alike those obtained from the rolling direction. Huh, used cross-rolling of $90^{\circ}$ degrees with reductions of $20 \%, 38 \%$ and $80 \%$ on previous $75 \%$ cold-rolled aluminum slab, with typical deformation texture. He also estimated texture evolution by simulations based on the Taylor full constraints (FC). Simulation results showed that $80 \%$ cross-rolling is sufficient to reconstruct a typical fcc rolling texture as obtained by $75 \%$ cold rolling ${ }^{17}$.

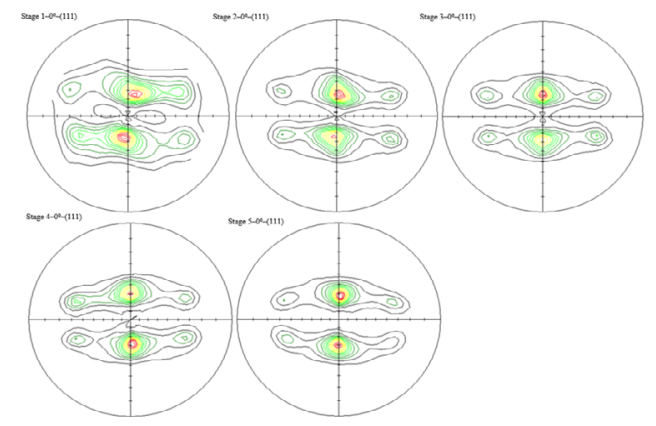

Figure 4. Pole figures progressing from the $1^{\text {st }}$ (drawn) to the $5^{\text {th }}$ (third ironing die) stage for samples taken at $0^{\circ}$ in relation to the rolling direction showing the (111) planes.

In our case, the rolling texture for rotation of $90^{\circ}$ behaves very similarly with the results obtained with Taylor's simulation for different degrees of deformation which are the different ironing steps. The deformation of $67 \%$ already reproduces the typical aluminum deformation texture. It was measured cross-rolling to $45^{\circ}$ and $90^{\circ}$, showing that the smaller is the cross-rolling angle, the smaller is the deformation required to recover the typical aluminum deformation texture. Besides this, the alignment of the grain with the flow direction is

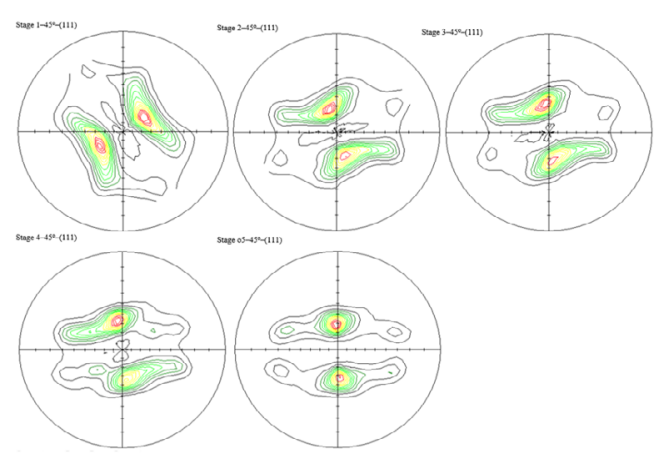

Figure 5. Pole figures progressing from the $1^{\text {st }}$ (drawn) to the $5^{\text {th }}$ (third ironing die) stage for samples taken at $45^{\circ}$ in relation to the rolling direction showing the (111) planes.

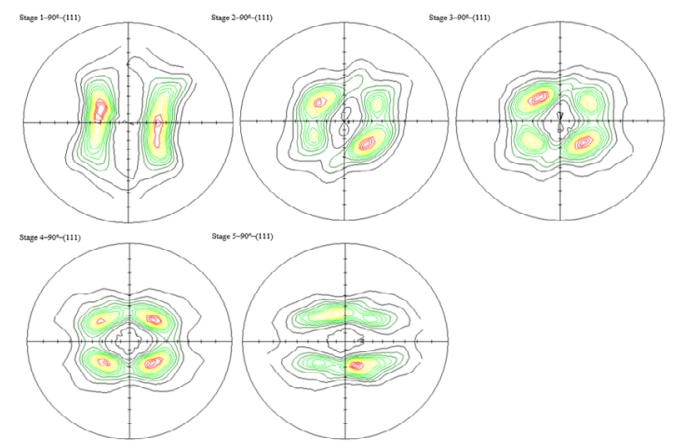

Figure 6. Pole figures progressing from the $1^{\text {st }}$ (drawn) to the $5^{\text {th }}$ (third ironing die) stage for samples taken at $90^{\circ}$ in relation to the rolling direction showing the (111) planes.

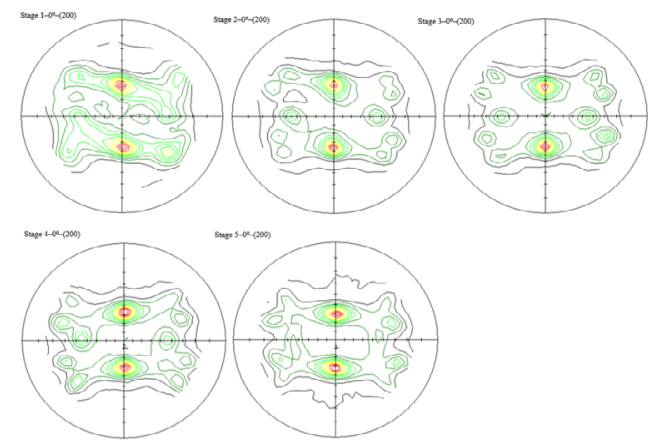

Figure 7. Pole figures progressing from the $1^{\text {st }}$ (drawn) to the 5 th (third ironing die) stage for samples taken at $0^{\circ}$ in relation to the rolling direction showing the (200) planes.

mentioned by Merchant when observing the microstructure resulting from the second draw, here called redraw $\left(2^{\text {nd }}\right.$ stage $)^{15}$. The total area percent reduction of $52 \%$ mentioned in Merchant's work is approximate to the $48 \%$ used in the present work for the redraw operation. This rotation/alignment with the flow (ironing) direction is also mentioned in relation to microbands detected at the top wall of the can after the $3^{\text {rd }}$ ironing operation before the metal is heated in the curing oven ${ }^{15}$. A possible explanation for the rotating pole figures is the gradual alignment of the grains with the metal flow 


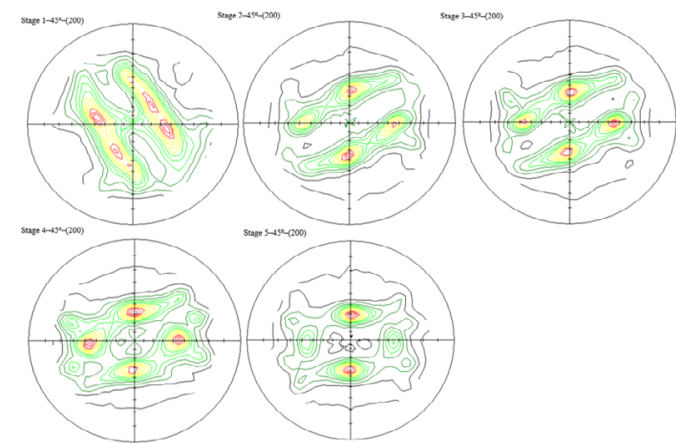

Figure 8. Pole figures progressing from the $1^{\text {st }}$ (drawn) to the $5^{\text {th }}$ (third ironing die) stage for samples taken at $45^{\circ}$ in relation to the rolling direction showing the (200) planes.

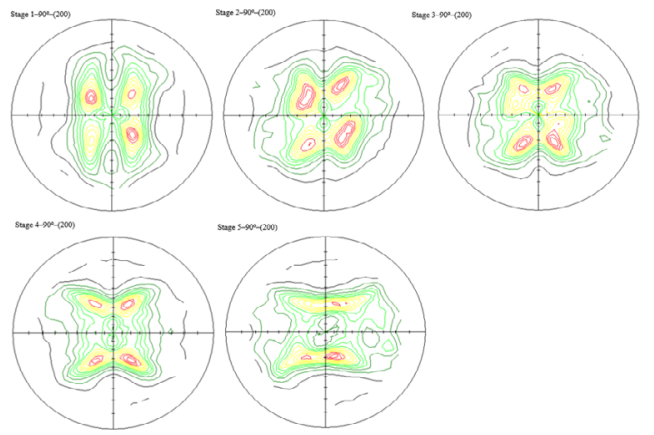

Figure 9. Pole figures progressing from the $1^{\text {st }}$ (drawn) to the $5^{\text {th }}$ (third ironing die) stage for samples taken at $90^{\circ}$ in relation to the rolling direction showing the (200) planes.

direction, which would continue if extra ironing operation were to happen. In this sense, a completely new "rolling" direction would be created for the cylindrical body, parallel to the original at the can wall, if the plastic deformation of thinning the walls would continue indefinitely. This rotation or alignment of the grains could also result in a reduction of earing intensity as the ironing progresses indefinitely.

\subsection{Orientation distribution figures}

Using the data gathered by the $0^{\circ}$ samples orientation distribution functions (ODF) were generated for each of the intermediate steps. Adding the coil ODF as the original starting texture an intensity comparison was realized with the intermediate steps. What is noticeable from the texture intensity evolution is that a sharpening of the copper $\{112\}<111>$ deformation texture occurs up to the $3^{\text {rd }}$ stage ( $1^{\text {st }}$ ironing die) and slight decreases afterwards while the other deformation texture, brass $\{110\}<112>$ and $S\{123\}<634>$, , behaves in a different way, losing intensity up to the $3^{\text {rd }}$ stage to regain some at the final stage studied. Another noticeable change can be seen in the cube texture $\{001\}<100>$ that seems to linearly decrease in intensity from the strain hardened coil to the further cold worked the final cylindrical body. The
ODFs of the coil, shown in Figure 10, and the intermediate steps are illustrated in Figures 11 through 16. In addition, a graph showing the texture intensity evolution through the five steps can be seen in Figure 17.

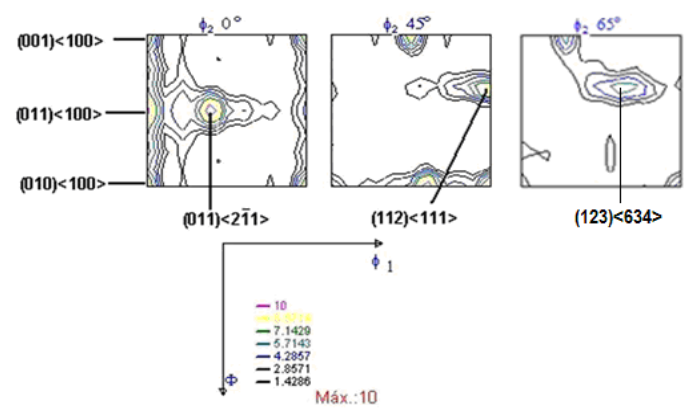

Figure 10. Orientation distribution function of aluminum alloy 3104-H19, showing Cube $\{001\}<100>$, Copper $\{112\}<111>$, Goss $\{110\}<001>$, and Brass $\{110\}<112>$ textures, conducive to the presence of cups with 6 ears commonly used in the can body manufacturing.
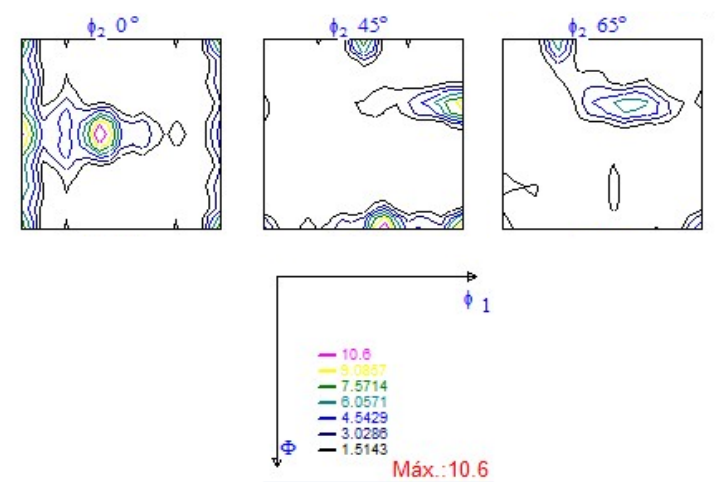

Figure 11. Orientation distribution function of AA 3104-H19 coil considered here the original texture for intensity variation comparisons through the intermediate steps.
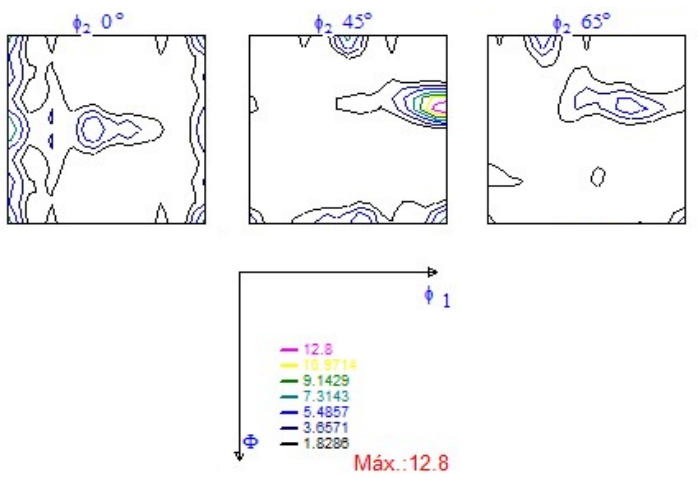

Figure 12. Orientation distribution function of the first stage (drawn cup). 

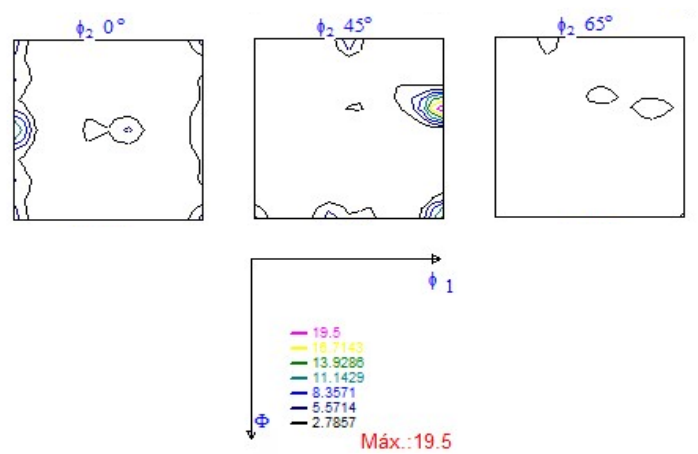

Figure 13. Orientation distribution function of the second stage (redraw cup).
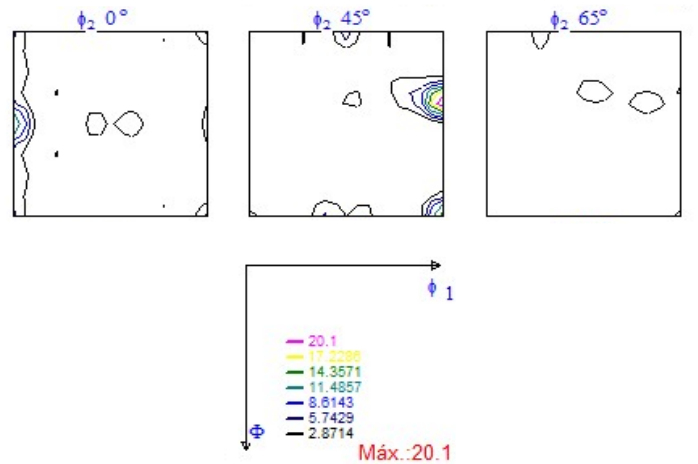

Figure 14. Orientation distribution function of the third stage ( $1^{\text {st }}$ ironing die).
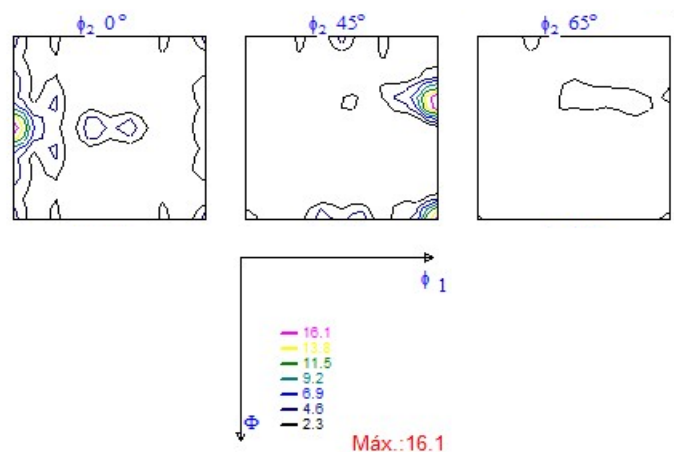

Figure 15. Orientation distribution function of the fourth stage ( $2^{\text {st }}$ ironing die).
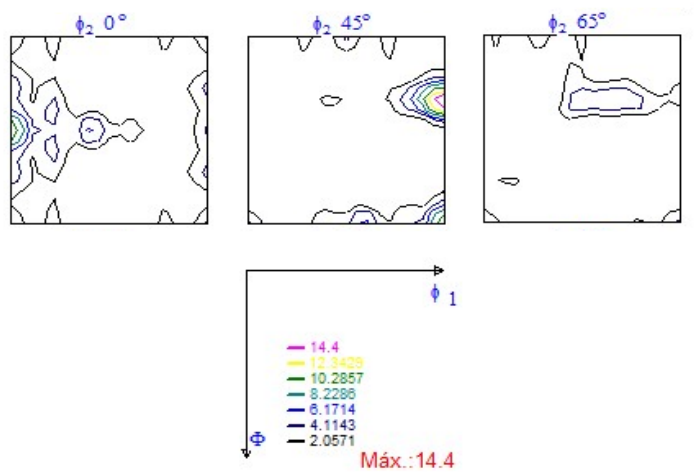

Figure 16. Orientation distribution function of the fifth stage $\left(3^{\text {st }}\right.$ ironing die).

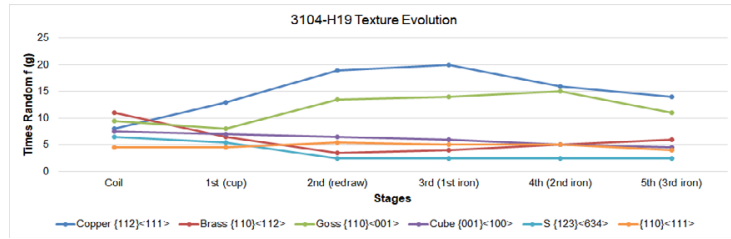

Figure 17. AA 3104-H19 crystallographic evolution from coil to final cylindrical body after five intermediate steps.

\section{Conclusions}

In the present paper the crystallographic texture evolution of aluminum alloy 3104 in the Drawn and Wall Ironing (DWI) Process in, samples acquired at $0^{\circ}, 45^{\circ}$, and $90^{\circ}$ in relation to the original sheet rolling direction was studied. Crystallographic texture continues to change from the drawn cup through the ironing stages. For samples gotten from the rolling direction $\left(0^{\circ}\right)$, there is a slight sharpening of the texture originally present in the drawing stage up until the $5^{\text {th }}$ stage. Samples removed at $45^{\circ}$ and $90^{\circ}$ in relation to the rolling direction display a pole figure rotation in the direction of the metal flow and this rotation is assumed to be an alignment of the grain with the plastic flow of the material. The final texture in all direction is near to typical aluminum deformation texture. The differences for samples taken at $0^{\circ}$ are described below:

- The copper $\{112\}<111>$ deformation texture increases in intensity after the final ironing stage in relation to the texture intensity found in the coil.

- The brass $\{110\}<112>$ and $S\{123\}<634>$ deformation texture decreases in intensity after the final ironing stage in relation to the texture intensity found in the coil.

- The cube $\{001\}<100>$ recrystallization texture decreases steadily from the original coil intensity thought the five intermediate steps until the final ironing.

These results could help the use texture-based polycrystalplasticity model to be able to predict earing profiles of $\mathrm{Al}$ can, once they provide more information about the behavior of texture during different stages of deep drawing at different angles related to initial sheet rolling direction

\section{References}

1. Engler O. Control of texture and earing in aluminium alloy AA 3105 sheet for packaging applications. Materials Science and Engineering: A. 2012;538:69-80.

2. Engler O, Hirsch J. Polycrystal-plasticity simulation of six and eight ears in deep-drawn aluminum cups. Materials Science and Engineering: A. 2007;452-453:640-51.

3. Engler O, Crumbach M, Li S. Alloy-dependent rolling texture simulation of aluminium alloys with a grain-interaction model. Acta Materialia. 2005;53(8):2241-57. 
4. Dalland O, Nes E. Origin of cube texture during hot rolling of commercial Al-Mn-Mg alloys. Acta Materialia. 1996;44(4):1389411.

5. Engler O, Mertens N, Van Dam P. Texture-based design of a convoluted cut-edge for earing-free beverage cans. Journal of Materials Processing Technology. 2011;211(7):1278-84.

6. Folle LF, Silveira Netto SE, Schaeffer L. Analysis of the manufacturing process of beverage cans using aluminum alloy. Journal of Materials Processing Technology. 2008;205(13):347-52.

7. Korhonen AS. Drawing force in deep drawing of cylindrical cup with flat-nosed punch. Journal of Engineering for Industry. 1982;104(1):29-37.

8. Deneuville $\mathrm{P}$, Lecot $\mathrm{R}$. The study of friction in ironing process by physical and numerical modelling. Journal of Materials Processing Technology. 1994;45(1-4):625-30.

9. Alexander DTL, Greer AL. Solid-state intermetallic phase tranformations in 3XXX aluminium alloys. Acta Materialia. 2002;50(10):2571-83.

10. Kang K. Impact of die wear and punch surface textures on aluminium can wall. Wear. 2009;266(9-10):1044-9.
11. Korhonen AS. On the work-hardening of AA 3104-H19 aluminum alloy. Journal of Materials Engineering and Performance. 2013;22(2):505-11.

12. Yu TM, Brooks CR, Goodrich S. The effect of cold working and annealing practice on earing in $3104 \mathrm{Al}$ alloy sheet. Materials Characterization. 1993;30(4):251-9.

13. Saha PK, Wilson WRD, Timsit RS. Influence of surface topography on the frictional characteristics of 3104 aluminum alloy sheet. Wear. 1996;197(1-2):123-9.

14. Hosford WF, Duncan JL. The aluminum beverage can. Scientific American. 1994;271(3):48-53.

15. Merchant HD, Hodgson DS, O'Reilly I, Embury JD. Structure and property evolution during drawing and wall ironing of aluminum alloy 3004. Materials Characterization. 1990;25(3):251-61.

16. Schünemann M, Ahmetoglu MA, Altan T. Prediction of process conditions in drawing and ironing of cans. Journal of Materials Processing Technology. 1996;59(1-2):1-9.

17. Huh MY, Cho SY, Engler O. Randomization of the annealing texture in aluminum 5182 sheet by cross-rolling. Materials Science and Engineering: A. 2001;315(1-2):35-46. 